\title{
Episodic Ataxia Type 1: A Neuronal Potassium Channelopathy
}

\author{
Sanjeev Rajakulendran,* Stephanie Schorge, ${ }^{*}$ Dimitri M. Kullmann, ${ }^{\dagger}$ and Michael G. Hanna* \\ *Department of Molecular Neuroscience, Centre for Neuromuscular Disease, and ${ }^{\dagger}$ Department of Clinical and Experimental \\ Epilepsy, Institute of Neurology, University College London, Queen Square, London WC1N 3BG, United Kingdom
}

Summary: Episodic ataxia type 1 is a paroxysmal neurological
disorder characterized by short-lived attacks of recurrent mid-
line cerebellar dysfunction and continuous motor activity. Mu-
tations in $K C N 1 A$, the gene encoding Kv1.1, a voltage-gated
neuronal potassium channel, are associated with the disorder.
Although rare, the syndrome highlights the fundamental fea-
tures of genetic ion-channel diseases and serves as a useful

\section{INTRODUCTION}

Dysfunction of neuronal ion channels is now understood to cause a number of paroxysmal neurological diseases. ${ }^{1-5}$ With advances in molecular biology and the completion of the human genome project, these genetically determined channelopathies are increasingly recognized in clinical practice.

The episodic ataxias are inherited syndromes characterized by intermittent cerebellar dysfunction in individuals with otherwise essentially normal brain function. ${ }^{2,6-10}$ Two main forms are recognized, episodic ataxia type 1 and type 2 (EA-1 and EA-2), both of which are autosomal dominant. The episodic ataxias exemplify the phenomenon of phenotypic convergence, in that EA-1 is caused by mutations in the voltage-gated potassium channel gene, KCNAI, ${ }^{11-18}$ but mutations in the gene CACNAIA, which encodes the voltage-gated P/Qtype calcium channel, are associated with EA-2. ${ }^{19-26}$ Although individually rare, these disorders have provided unprecedented insight into the complex interplay of ion channels and neuronal circuits, and have raised the possibility that mutations in ion channels underlie some of the more common neurological diseases such as epilepsy and migraine.

Address correspondence and reprint requests to: Michael G. Hanna, BSc(Hons) MD, FRCP, Centre for Neuromuscular Disease, Department of Molecular Neuroscience, Institute of Neurology, University College London, Queen Square, London WC1N 3BG, United Kingdom.E-mail:mhanna@ion.ucl.ac.uk. model for understanding more common paroxysmal disorders, such as epilepsy and migraine. This review examines our current understanding of episodic ataxia type 1 , focusing on its clinical and genetic features, pathophysiology, and treatment. Key Words: Episodic ataxia, channelopathies, myokymia, potassium channel.
The voltage-gated potassium channel Kv1.1, which is encoded by the KCNA 1 gene associated with EA-1, ${ }^{11-18}$ contributes to the regulation of neuronal excitability and is widely expressed in the nervous system. With the identification and characterization of newer mutations of KCNA1 in EA-1 kindreds, the phenotypic spectrum of the disorder has widened considerably beyond the original description of a purely cerebellar syndrome. This review examines the protean clinic manifestations of EA-1. The mechanistic link between genotype and phenotype is further considered, along with an outline of the molecular and cellular processes involved.

\section{CLINICAL FEATURES}

In 1975, Van Dyke et al. ${ }^{27}$ first described a family in which 11 members over three generations experienced periodic ataxia and continuous muscle movement. The onset of the disorder was between the ages of 2 and 12 years, and the affected individuals experienced attacks of generalized ataxia, jerking movements of the head, stiffening of the body, and carpal spasms, as well as subjective sensations including vertigo, dizziness, blurred vision, and diplopia. These attacks would last on average 3 minutes and would be provoked by anxiety, excitement, fatigue, hunger, and voluntary movement (kinesigenic stimulation).

Hanson et al. ${ }^{28}$ subsequently described in 1976 another family, in which the mother and her two children had intermittent attacks of shaking and titubation with 
dysarthria and abnormal hand posturing. The mother, who was born with a clubfoot, described having had episodes of shaking since the age of 4 or 5 years. Episodes occurred several times a month and lasted 10 minutes. During these episodes, her legs would feel weak, her voice would become slurred and she would develop a tremor of the head. In addition, she had continuous rippling muscle movements in her legs, fine twitching of her eyelids, and a tremor involving her hands at rest. Her two children were both born with abnormal posture of the feet. At birth, both the children's hands were clamped shut and described as difficult to pry open. They both went on to develop intermittent episodes of shaking, loss of balance, slurred speech, and stiffening of the body.

Brunt and Van Weerdan ${ }^{10}$ in 1990 described the largest family known to date affected by paroxysmal ataxia and continuous myokymia. Twenty-eight members over five generations were diagnosed as having the condition. The onset, frequency, nature of attacks, and precipitants were comparable with previously described families. ${ }^{8,26}$ Within the family, there was inter-individual variation with respect to symptoms, duration, and intensity. For example, one boy for many years had attacks of ataxia exclusively during intercurrent illness. The presence of myokymia was also variable. Close examination of half the members demonstrated fine rippling of the muscles, and in another one fourth, myokymia was evident as small lateral finger movements. In all of the affected family members who had EMG examinations, myokymic discharges were clearly demonstrated.

Since the description of the first EA-1 kindred by Van Dyke et al., ${ }^{27}$ a further 19 unrelated families have been described in the literature. ${ }^{8,11-18,28-31}$ Within this group, more than 100 individuals have been identified as having the phenotype of episodic ataxia and myokymia, the two cardinal features of EA-1. It is becoming increasingly apparent that wide phenotypic differences exist both be- tween families and between individuals of the same family. Although the full spectrum of phenotypic variations remains to be established, a number of core clinical features have emerged.

Clinically, EA-1 usually declares itself in the first or second decade of life. Patients experience disabling attacks of midline cerebellar dysfunction, manifesting as truncal and limb ataxia, dysarthria, and visual symptoms such as oscillopsia and visual blurring. These symptoms are often accompanied by nausea and headache. A coarse tremor of the arms and head titubation are clinically evident in certain kindreds. These attacks are triggered by physical and emotional stress, chemical stressors, startle, and sudden postural changes and can last from seconds to minutes. The frequency of these ataxic spells can vary among individuals, from recurrent daily ictal episodes to infrequent attacks occurring a few times a year. The episodes terminate spontaneously. Some patients find that resting or sleeping at the onset helps curtail the episode. Interictally, patients are asymptomatic, with a normal neurological examination. The disease is nonprogressive, and the attack frequency commonly decreases with age.

The second cardinal feature of EA-1 is the presence of continuous interictal motor activity in the form of myokymia or neuromyotonia that is a consequence of peripheral nerve hyperexcitability. The term myokymia denotes spontaneous skeletal muscle contractions that produce a rippling quality. These fine, rippling movements of muscle can be observed in the limbs and around the eyes, and are also evident as small-amplitude sideto-side movements of the fingers in the outstretched hands. Myokymia in EA-1 patients is often subclinical, although invariably evident on electromyography studies (FIG. 1).

Episodic ataxia type 2 is the other well-characterized paroxysmal cerebellar disorder. ${ }^{2,6,32,33}$ Although it has

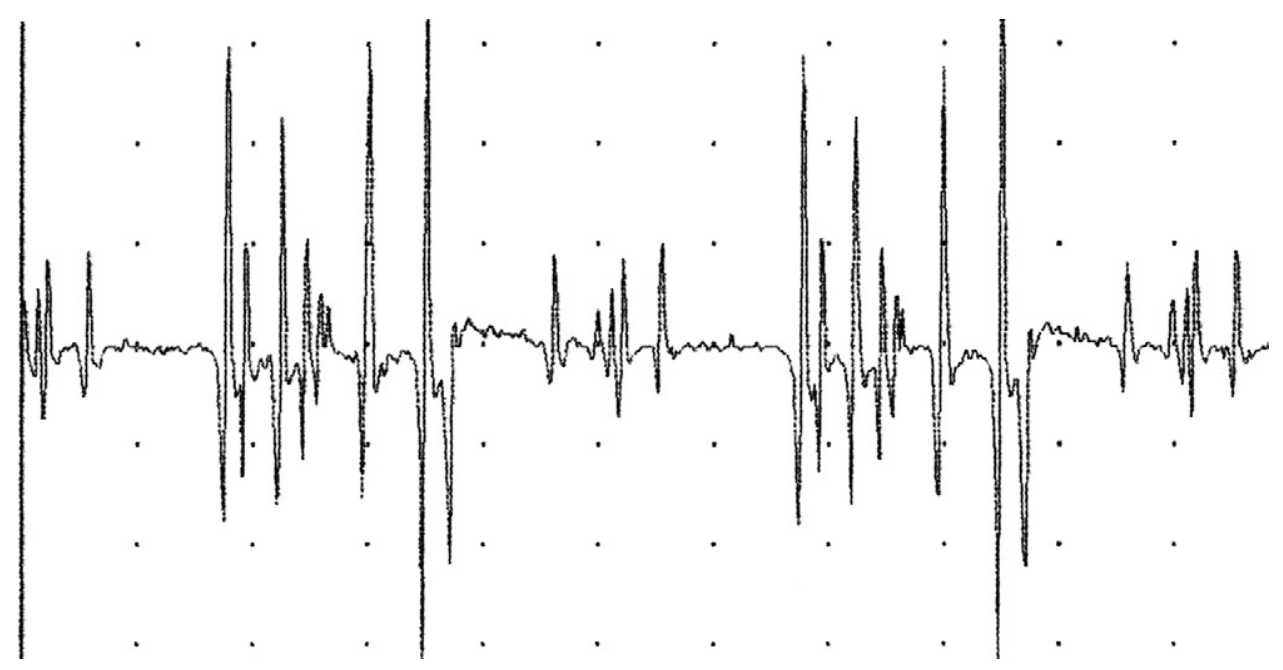

FIG. 1. Electromyographic tracing of myokymia. 
similarities to EA-1, several features help to distinguish it. First, EA-2 is more prevalent. The duration of the attack in EA-2 is measured in hours to days, and each ictus is commonly associated with nausea, vomiting, vertigo, and occasionally diplopia. More than half of patients with EA-2 experience a severe migrainous headache during an attack. The migrainous component is notable, in that familial hemiplegic migraine is an allelic disorder of the P/Q-type calcium channel ${ }^{34,35}$ and patients often have overlapping features. Weakness during or preceding an attack has also been described. Although myokymia is not a feature in EA-2, patients often develop persistent interictal downbeating nystagmus that is present in all directions of gaze. Moreover, in these patients, a progressive cerebellar syndrome often supervenes in later years. Indeed, cerebellar atrophy, notably of the anterior vermis, is evident on MRI. ${ }^{36}$ Attacks in EA-2 patients may be precipitated by stress or intercurrent illness but not by sudden movements (in contrast to EA-1). The efficacy of drugs such as acetazolamide is also more marked in EA-2 patients. ${ }^{7}$

With the discovery of novel mutations in EA-1, the phenotypic spectrum of the disorder has widened. In addition to the classical description, phenotypic variants include EA-1 with partial epilepsy, ${ }^{14,17}$ EA-1 without myokymia, ${ }^{37}$ and even isolated severe neuromyotonia. ${ }^{14}$ Eunson et al. ${ }^{14}$ described a family with a KCNAl gene mutation in which the proband, a 3-year-old boy, presented with increased tone in his limbs, his fists partially clenched, and small semirhythmical lateral movements of his fingers and rippling movements of his calf and hamstrings. His EMG confirmed continuous generalized myokymic activity. His 39-year-old father had no history of episodic ataxia or muscle stiffness, but displayed subtle myokymia of his dorsal interrossei. Isolated neuromyotonia has been previously described in autoimmune Isaacs' syndrome or acquired neuromyotonia, in which antibodies against the voltage-gated potassium channel result in its dysfunction; however, this family represents the first reported case of isolated neuromyotonia caused by a mutation in the KCNAl gene.

In a few patients with EA-1, longer lasting episodes have also been reported. A number of different neuromuscular findings are recognized, including distal wasting with contractures, shortening of the Achilles tendon in children, and transient postural abnormality in infants such as flexion of the fingers, wrists, elbows, and knees. $^{16}$

Kinali et al. ${ }^{38}$ reported a case in one family in which the same mutation of the KCNAl gene in the mother and son resulted in two different clinical phenotypes. The son presented in infancy with generalized muscle stiffness and motor developmental delay. He was also found to have mildly dysmorphic features, short stature, and an abnormal gait. His increased muscle tone resulted in marked kyphoscoliosis, elbow contractures, and shortening of the Achilles tendon. His EMG demonstrated marked generalized myokymia. The boy's mother presented some years later with typical features of EA-1. On examination, she had myokymia and mild skeletal abnormalities.

This family ${ }^{38}$ was found to have the same mutation as another family ${ }^{17}$ with EA-1 accompanied by contractures and epilepsy (see next section). Recently, a 10-year-old girl with EA-1 was found to have distal weakness with paresis of the extensors of the feet and prolonged spells of limb stiffness lasting up to 12 hours. ${ }^{39}$ There is also heterogeneity in the response to treatment ${ }^{40}$ with some kindreds being particularly resistant to drugs. ${ }^{14}$

\section{EPILEPSY AND EA-1}

The prevalence of seizures is overrepresented in EA-1 family members, compared with unaffected members. To date, 11 individuals from four unrelated families have been reported to have epilepsy. ${ }^{10,17,27,37}$ Van Dyke et al. ${ }^{27}$ described a female with generalized motor seizures and an abnormal EEG who had a partial response to phenytoin. Brunt and van Weerdan ${ }^{10}$ in 1990 identified three members of an EA-1 family with 28 affected members who had abnormal EEGs. The family harbored the V174F missense mutation in the KCNAl gene.

Zuberi et al. ${ }^{17}$ described a Scottish family with EA-1 in whom a point mutation (T226R) in KCNAl was identified. Of the five affected individuals in the family, two had epilepsy supported by ictal EEG recordings. The propositus was a 3-year-old boy who presented at 7 weeks with recurrent episodes of apnea and cyanosis. The episodes consisted of head-turning and eyes deviating to the same side, flickering of the eyelids, and lip-smacking. The ictal EEG demonstrated rhythmical slow-wave activity over the right hemisphere, becoming spike-and-wave complexes that subsequently spread to the left hemisphere. A diagnosis of complex partial seizures was made, and the patient was successfully treated with carbamazepine. The boy's paternal aunt was also diagnosed with EA-1 and epilepsy. She presented in early infancy with marked postural deformities and was initially diagnosed as having atypical familial arthrogryposis. Between the ages of 9 and 10 years, she began having attacks of episodic ataxia and seizures, clinically considered to be partial followed by secondary generalization. Although the ataxic episodes were clearly distinguished from seizures, her EEGs on two occasions were normal and she did not respond well to phenytoin or sodium valproate.

Eunson et al. ${ }^{14}$ reported a further family in which the mother had a phenotype of both tonic-clonic and partial seizures with long-standing myokymia; her 3-year-old son had nonfebrile tonic-clonic seizures. Both family 
members were found to have a mutation in the KCNAI gene (A242P) but neither had any ataxic episodes.

Patients with EA-1 are approximately 10 times more likely to develop epilepsy than are normal individuals, implicating KCNA1 mutations as a pathogenic susceptibility factor for epilepsy. ${ }^{17}$ In support of this, a mouse knock-out of KCNAl has been described to have an epilepsy phenotype. ${ }^{41}$ Moreover, mutations in two related voltage-gated potassium channel genes, $K C N Q 2$ and $K C N Q 3$ on chromosome arms 20q and 8q, respectively, have been implicated in the pathogenesis of benign familial neonatal convulsions (BFNC). ${ }^{42-46}$ The seizure type in EA-1 patients includes both generalized ${ }^{41}$ and partial seizures. Potassium channels determine the excitability of neurons, and drugs that block potassium channels are proconvulsant in humans. ${ }^{47,48}$ It is possible that dysfunction of potassium channels may be relevant to other epilepsies in humans, particularly if they lower seizure threshold. It is still unclear why only certain individuals with EA-1 mutations develop epilepsy-although epigenetic factors may influence the phenotype.

A further link between $K C N A I$ and epilepsy is suggested by a recent study of the role of LGI-1, implicated in a rare autosomal dominant form of temporal lobe epilepsy, in modulating fast inactivation of Kv1.1. ${ }^{49}$ Other cellular roles of LGI-1 have been reported, ${ }^{50}$ however, and so this mechanistic link remains to be confirmed.

\section{Diagnosis of EA-1}

The most valuable investigation in patients suspected of having EA-1 is the EMG. An abnormal myokymic EMG is found in nearly all patients with EA-1, regardless of whether they have visible myokymia on examination. Typical features include continuous spontaneous repetitive motor unit discharges. Recurrent grouped discharges (doublets, triplets, and multiplets) are also seen. ${ }^{28}$ In some patients, a myokymic EMG is evident after the application of regional ischemia. ${ }^{40}$ Laboratory blood tests including creatine kinase are not affected by EA-1. A muscle biopsy is generally unhelpful in aiding diagnosis. An EEG may be informative, given the overrepresentation of epilepsy in EA-1 patients. In contrast to EA-2, in which cerebellar atrophy may be visible on MRI with progression of disease, EA-1 patients have unremarkable MRI features. Now that the gene defect responsible for EA-1 has been identified, screening for mutations in the KCNAl gene on chromosome 12 can help to provide genetic confirmation of the disorder.

\section{Molecular biology of EA-1}

Genetic linkage studies ${ }^{11,12,51}$ have mapped the EA-1 syndrome locus to chromosome band 12p13 and to mutations in the KCNAl gene, which encodes the voltagegated potassium channel subunit $\mathrm{Kv} \alpha 1.1$. This is the mammalian ortholog of the Shaker channel, the first potassium channel to be identified in the fruit fly, Drosophila melanogaster. Eighteen missense mutations and one premature stop codon in the carboxyl terminus have been identified in EA-1 patients ${ }^{11-18}$ (Table 1). These mutations are understood to be pathogenic, and not polymorphisms, because they are not present in large numbers of control chromosomes in the background population, nor are they present in family members without EA-1. The mutations all affect highly conserved residues in the channel and are distributed throughout the peptide chain.

A detailed description of the structure and function of the voltage-gated potassium channel is beyond the scope of this review. ${ }^{3,52} \mathrm{~A}$ few basic principles, however, are necessary to appreciate the effects of mutations on the biophysical properties of the channel.

Kv1.1 channels open upon depolarization and mediate neuronal repolarization following the action potential, thus regulating the electrical excitability of nerve and muscle fibers. Native Kv1.1 channels consist of four homologous pore-forming $\alpha$-subunits ( $\operatorname{Kv} \alpha 1.1$ ), each containing six transmembrane-spanning segments (S1-S6), which are linked by intracellular and extracellular loops (FIG. 2A). The $\alpha$-subunits of the potassium channel share a similar structure with the other members of the voltage-gated channel superfamily, with each $\mathrm{Kv}$ subunit homologous to a single domain of sodium and calcium channels-each comprised of four homologous, potassium channel-like domains within a single molecule.

The crystal structure of mammalian $\mathrm{Kv} \alpha$-subunits has recently been resolved, ${ }^{53}$ revealing how the six transmembrane segments fold together to make a functional subunit (FIGS. 2B and 2C). The $\alpha$-subunits of these channels determine their ion selectivity and control the voltage-sensing functions of the ion channels. The S4 segment of the $\alpha$-chain contains several positively charged amino acids and acts as the voltage sensor of the channel, linking changes in membrane voltage to the opening of the channel pore. The S5-S6 loop forms the selectivity filter that ensures the channel is impermeable to all other ions except potassium. The $\mathrm{N}$ - and $\mathrm{C}$-termini of each subunit are cytoplasmic and play important roles in channel assembly and targeting. In addition to the four $\alpha$-subunits, the Kv1.1 channel also contains accessory cytoplasmic $\beta$-subunits, ${ }^{54}$ which associate with the $\alpha$-subunit in a 1:1 stoichiometry, such that four $\alpha$-subunits and four $\beta$-subunits combine to form the complete $\mathrm{Kv}$ channel complex.

The $\alpha$ - and $\beta$-subunit composition is subject to variability, such that $\mathrm{Kv} \alpha 1.1$ (the channel implicated in EA-1) may coassemble with other members of the $\mathrm{Kv}$ 
TABLE 1. Mutations identified in EA-1 patients

\begin{tabular}{|c|c|c|c|}
\hline $\begin{array}{l}\text { Mutation } \\
\text { (Segment Involved) }\end{array}$ & Phenotype & Functional Consequences & References \\
\hline V174F (S1) & EA-1 with epilepsy & Mutant channels are not functional & Adelman et al., ${ }^{58} 1995$ \\
\hline I177N (S1) & EA-1 & $\begin{array}{l}\text { Reduction in } \mathrm{K}^{+} \text {current } \\
\text { amplitude; alters channel } \\
\text { kinetics }\end{array}$ & Imbrici et al., ${ }^{63} 2003$ \\
\hline F184C (S1) & EA-1 & $\begin{array}{l}\text { Alters voltage dependence and } \\
\text { kinetics of activation }\end{array}$ & Adelman et al., ${ }^{58} 1995$ \\
\hline T226A (S2) & EA-1 & $\begin{array}{l}\text { Profound reduction in } \mathrm{K}^{+} \text {current } \\
\text { amplitude. Slowed activation } \\
\text { and deactivation kinetics }\end{array}$ & Zerr et al., ${ }^{61} 1998$ \\
\hline T226R (S2) & $\begin{array}{l}\text { EA-1 with epilepsy and } \\
\text { infantile contractures, } \\
\text { postural abnormalities, } \\
\text { skeletal deformities }\end{array}$ & $\begin{array}{l}\text { Reduction in } \mathrm{K}^{+} \text {current, with } \\
\text { mutant subunits exerting a } \\
\text { dominant negative effect }\end{array}$ & Zuberi et al., ${ }^{17} 1999$ \\
\hline T226M (S2) & EA-1 & $\begin{array}{l}\text { Profound reduction in } \mathrm{K}^{+} \text {current } \\
\text { amplitude; shift in threshold of } \\
\text { activation }\end{array}$ & Zerr et al., ${ }^{61} 1998$ \\
\hline T226K (S2) & Isolated myokymia & $\begin{array}{l}\text { No } \mathrm{K}^{+} \text {current, with mutant } \\
\text { subunits exerting a dominant } \\
\text { negative effect }\end{array}$ & Hisama et al., ${ }^{69} 2006$ \\
\hline R239S (S2) & EA-1 & Minimal $\mathrm{K}^{+}$current & Adelman et al., ${ }^{58} 1995$ \\
\hline A242P (S2) & Myokymia and seizures & $\begin{array}{l}\text { Profound reduction in } \mathrm{K}^{+} \text {current } \\
\text { amplitude }\end{array}$ & Eunson et al., ${ }^{14} 2000$ \\
\hline P244H (S2-S3 linker) & Isolated neuromyotonia & $\begin{array}{l}\text { Functionally no difference } \\
\text { between wild-type and mutant } \\
\text { channels }\end{array}$ & Eunson et al., ${ }^{14} 2000$ \\
\hline F249I (S2-S3 linker) & EA-1 & No detectable $\mathrm{K}^{+}$current & Zerr et al., ${ }^{62} 1998$ \\
\hline I262T (S3) & EA-1 with distal weakness & $\mathrm{N} / \mathrm{A}$ & \\
\hline G311S (S4-S5 linker) & EA-1 & Reduction in $\mathrm{K}^{+}$current & Zerr et al., ${ }^{61} 1998$ \\
\hline E325D (S4-S5 linker) & EA-1 & $\begin{array}{l}\text { Altered kinetics of activation and } \\
\text { voltage dependence }\end{array}$ & Adelman et al., ${ }^{58} 1995$ \\
\hline L329I (S5) & EA-1 & $\mathrm{N} / \mathrm{A}$ & \\
\hline S342I (S5) & $\begin{array}{l}\text { EA-1 without myokymia } \\
\text { seizures }\end{array}$ & N/A & \\
\hline V404I (S6) & EA-1 & $\begin{array}{l}\text { Relatively small effect on channel } \\
\text { properties; responds well to } \\
\text { treatment }\end{array}$ & Eunson et al., ${ }^{14} 2000$ \\
\hline V408A (S6) & EA-1 & $\begin{array}{l}\text { Minor alterations in kinetics of } \\
\text { activation and voltage } \\
\text { dependence }\end{array}$ & Adelman et al., ${ }^{58} 1995$ \\
\hline R417X (C-terminus) & Drug-resistant EA-1 & $\begin{array}{l}\text { Profound reduction in } \mathrm{K}^{+} \text {current } \\
\text { amplitude }\end{array}$ & Eunson et al., ${ }^{14} 2000$ \\
\hline
\end{tabular}

EA-1 $=$ episodic ataxia type $1 ; \mathrm{N} / \mathrm{A}=$ data not available.

subfamily, notably $\mathrm{Kv} \alpha 1.2$ and $\mathrm{Kv} \alpha 1.4 .^{55-57}$ There is also some variability in the identity of the $\beta$-subunit, thus increasing the range of channel stoichiometries. Depending on the identity of the $\alpha$-and $\beta$-subunits making up the channel, it can exhibit fast inactivation in the presence of continued depolarization. This is mediated by the insertion of a cytoplasmic peptide (which corresponds to the $\mathrm{N}$-terminus of an $\alpha$-subunit or of an accessory $\beta$-subunit) into the pore of the channel. The $\beta$-subunits also promote the surface expression of $\alpha$-subunits, enhance potassium current amplitude, and may modulate channel kinetics.

\section{Functional effects of EA-1 mutations in Kv1.1}

In vitro electrophysiological methods have helped considerably in elucidating the mechanisms by which mutations in the $\operatorname{Kv} \alpha 1.1$ channel subunit result in the EA-1 phenotype. Most studies of this nature have used heterologous expression systems in which channels containing the mutations associated with EA-1 are introduced into cells, such as Xenopus oocytes, that normally do not express abundant voltage-gated channels. The effects of these mutations on potassium channel function are then investigated by voltage-clamping and measuring the electrical current flowing in response to imposed changes 


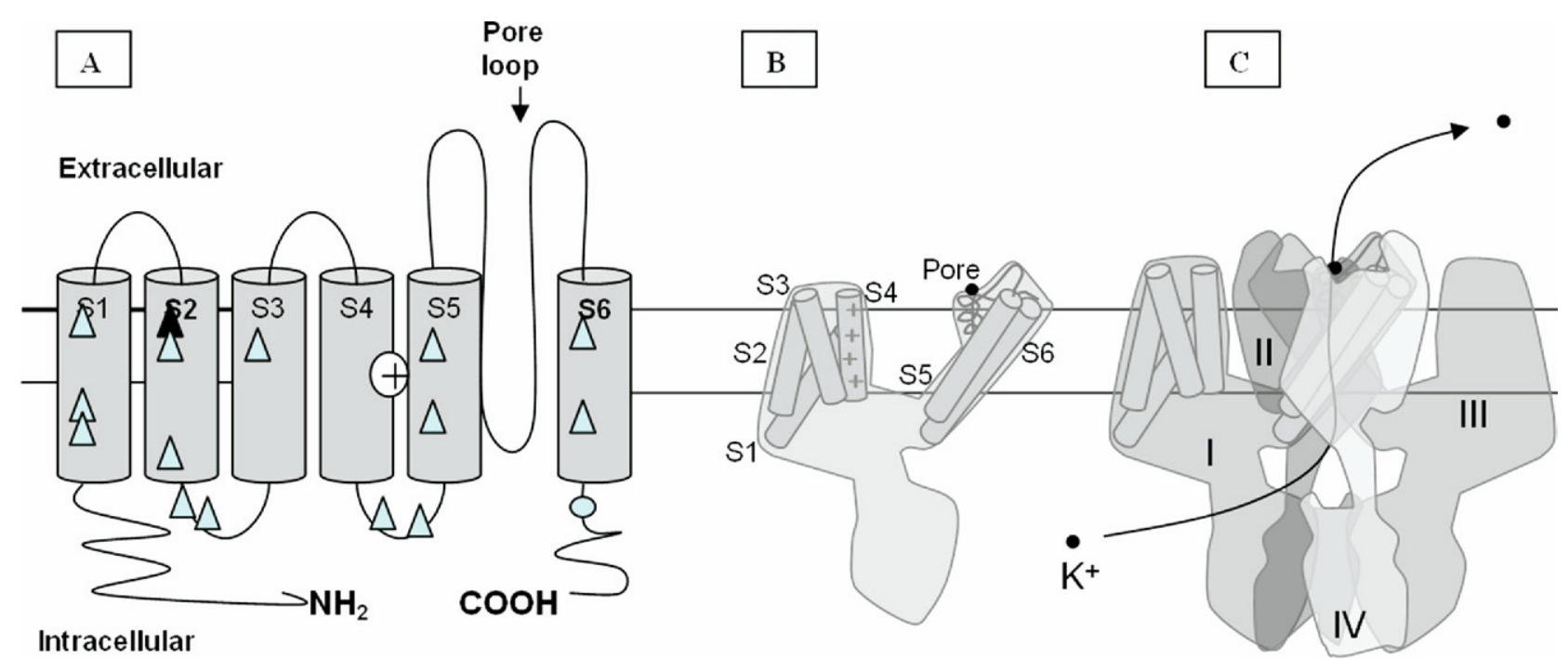

FIG. 2. (A) Structure of the Kv $\alpha 1.1$ channel subunit showing the six transmembrane segments (S1-S6), the voltage-sensing S4 segment, and the pore-lining loop between S5 and S6. Triangles indicate the positions of known missense mutations; the circle represents the R147 stop, which truncates most of the C-terminus. The black triangle represents the highly variable T226 site (for details, see text under Epilepsy and EA-1). (B) A depiction of the predicted structure of a single Kv1.1 subunit channel showing the position of the six transmembrane segments and the pore. (C) The predicted assembly of four $\alpha$-subunits to form a functional channel, with the location of the pore. For simplicity, the approximate locations of the transmembrane segments are indicated in domain I only.

in transmembrane voltage. Several studies have shown that mutant Kv1.1 subunits result in a significant reduction in peak potassium current amplitude relative to wildtype currents. ${ }^{14,17,58-64}$ The reduction varies, depending on the mutation, and ranges from virtually undetectable to a current amplitude comparable with wild-type channels. Thus far, no mutations have been found that increase the currents from these channels.

Alterations in the voltage threshold and gating properties of potassium channels have also been demonstrated. Some mutations alter the rate of activation and inactivation, and others shift the activation threshold to more depolarized levels. ${ }^{62}$ The end result is a reduction in potassium flux through the channel. If one considers that patients with EA-1 are heterozygous and that Kv1.1 is a tetrameric protein, then the Kv1.1 channels in patients are likely to be assembled from a mix of normal and mutant subunits encoded by their two copies of KCNA1. Studies attempting to reproduce the in vivo condition have coexpressed mutant and normal $\mathrm{Kv} \alpha 1.1$ subunits, and this has resulted in potassium current densities that were intermediate between homomeric mutant and normal channels on their own. ${ }^{17,62}$ The view that mutant channels exerted a dominant negative effect on current amplitude is inferred when the mixture of mutant and normal channels gives less current than half the normal channels alone.

Some mutations interfere with fast inactivation, by hampering the insertion of the inactivating peptide into the cytoplasmic pore. ${ }^{65,66}$ Thus, depending on whether $\mathrm{Kv} \alpha 1.1$ coassembles with subunits that confer fast inactivation, a given mutation may have highly variable ef- fects on neuronal excitability. Because the normal partners of $\mathrm{Kv} \alpha 1.1$ show cell-type and regional diversity in the nervous system, ${ }^{67}$ this phenomenon, together with differences in the degree of loss of function, may go some way toward explaining the phenotypic differences associated with distinct mutations.

A further insight into the effects of altered potassium channel function in terms of $\mathrm{Kv} \alpha 1.1$ mutations may be deduced from animal studies. $\mathrm{Kv} \alpha 1$ 1.1-null mice, which have had the KCNAl gene deleted, have a phenotype of ataxia, seizures, and myokymia. ${ }^{41}$ In one study, a mouse knock-in model of the V408A mutation was constructed by introducing the mutation by homologous recombination. ${ }^{68}$ Homozygous V408A/V408A mice died on embryonic day 3 , but heterozygous $\mathrm{V} 408 \mathrm{~A} /+$ mice were viable and had stress-induced loss of coordination and showed improvement with acetazolamide similar to that seen for EA-1 in humans.

Evidence linking the degree of potassium current impairment to the severity of disease has come from studies in which mutations associated with a severe phenotype including seizures and drug-resistance (R147 stop which truncates the C-terminus) dramatically reduce the potassium current, whereas mutations associated with a relatively benign phenotype of neuromyotonia alone with no ataxia ( $\mathrm{P} 244 \mathrm{H})$ did not alter the current amplitude. This may in part explain the phenotypic variability observed with EA-1. To date, no mutations in patients have been found that would be expected to cause a complete deletion of the gene. The single mutation that truncates the subunit, R147stop, is found at the extreme end of the subunit. It is likely that severe phenotypes, such as those 
TABLE 2. The response of EA-1 families to medications

\begin{tabular}{|c|c|c|c|}
\hline Mutation & Phenotype & Response to Medication & References \\
\hline F184C & EA-1 and myokymia & Partial response to phenytoin & Van Dyke et al., ${ }^{27} 1975$ \\
\hline V174P & EA-1 and myokymia & $\begin{array}{l}\mathrm{ACZ} \text { ineffective in one member; phenytoin } \\
\text { reduced myokymia in one member }\end{array}$ & Gancher and Nutt, ${ }^{8} 1986$ \\
\hline V174P & EA-1 and myokymia & $\begin{array}{l}\text { In } 12 \text { members tested, ACZ reduced } \\
\text { frequency of attacks in } 8\end{array}$ & Brunt and van Weerdan, ${ }^{10} 1990$ \\
\hline E325D & EA-1 and myokymia & $\begin{array}{l}\text { ACZ reduced frequency and severity of } \\
\text { attacks in } 3 \text { members }\end{array}$ & Lubbers et al., ${ }^{40} 1995$ \\
\hline T226R & $\begin{array}{l}\text { EA-1 and partial seizures, } \\
\text { postural abnormalities }\end{array}$ & $\mathrm{ACZ}$ reduced attacks in 1 member & Zuberi et al., ${ }^{17} 1999$ \\
\hline A242P & $\begin{array}{l}\text { Partial epilepsy and } \\
\text { myokymia }\end{array}$ & $\begin{array}{l}\text { Antiepileptic medication improved } \\
\text { myokymia }\end{array}$ & Eunson et al., ${ }^{14} 2000$ \\
\hline $\mathrm{P} 244 \mathrm{H}$ & Isolated neuromyotonia & $\mathrm{N} / \mathrm{A}$ & Eunson et al., ${ }^{14} 2000$ \\
\hline $\mathrm{R} 417 \mathrm{X}$ & Drug-resistant EA-1 & $\begin{array}{l}\text { No improvement with } \mathrm{ACZ} \text { and } \\
\text { antiepileptics }\end{array}$ & Eunson et al., ${ }^{14} 2000$ \\
\hline V404I & EA-1 and myokymia & Carbamazepine improved attacks & Eunson et al., ${ }^{14} 2000$ \\
\hline L329I & EA-1 and myokymia & $\begin{array}{l}\text { Carbamazepine significantly reduced } \\
\text { frequency of attacks in } 8 \text { members }\end{array}$ & Hand et al., ${ }^{30} 2001$ \\
\hline T226R & $\begin{array}{l}\text { Severe neuromyotonia } \\
\text { and skeletal deformities }\end{array}$ & $\begin{array}{l}\text { In } 1 \text { member, phenytoin improved } \\
\text { neuromyotonia; in } 1 \text { other member, } \\
\text { carbamazepine reduced frequency and } \\
\text { severity of ataxic attacks }\end{array}$ & Kinali et al., ${ }^{38} 2004$ \\
\hline
\end{tabular}

$\mathrm{ACZ}=$ acetazolamide; EA-1 = episodic ataxia type 1; N/A = data not available.

seen in mouse knockouts, would result from earlier truncations and that these would extend the phenotypic range further.

The relationship between mutation and phenotype is further complicated by the finding that four different mutations in KCNAl change the amino acid threonine 226 (Table 1). This amino acid is conserved widely, from fruit fly to humans. ${ }^{69}$ Although functional studies indicate that altering this amino acid in all cases causes a drastic reduction in potassium current (in two cases with dominant negative effects), the phenotype is highly variable, ranging from typical EA-1 to isolated myokymia to EA-1 with epilepsy and abnormal posturing. This suggests that virtually identical defects in channel function can lead to diverse manifestations of disease.

The question to be answered is how the observed reduction in potassium current results in the EA-1 phenotype. The Kv1.1 channel is widely expressed both in the CNS and peripheral nerves, particularly in GABAergic basket cells of the granule cell layer and in the juxtaparanodal regions of motor axons. ${ }^{70,71}$ The continuous motor fiber activity in neuromyotonia is generated by hyperexcitability of motor axons. The mechanism is similar to that which has been proposed in acquired neuromyotonia, which is associated with antibodies against the voltage-gated potassium channels in the peripheral motor nerves. The mutations in the $\mathrm{Kv} \alpha 1.1$ channel subunit lead to a reduction in potassium permeability that results in prolongation of the action potential and failure to repolarize. ${ }^{72}$ This failure to repolarize gives rise to the repetitive myokymic discharges.
The mechanism of ataxia is harder to explain. GABAergic basket cells have a marked inhibitory effect on Purkinje cells and are therefore ideally placed to regulate cerebellar output. If Kv1.1 is normally enriched in these cells, then mutations in the KCNAl gene resulting in dysfunction of the Kv1.1 channel function might be hypothesized to impair the cerebellar modulation of movement and so result in ataxia. ${ }^{73}$ This model, however, fails to explain why cerebellar dysfunction is intermittent, or indeed why attacks are precipitated by stress or startle.

It has recently been proposed that spreading acidification, akin to cortical spreading depression, may occur in the cerebellar cortex. ${ }^{74}$ Whether this occurs during an ictus remains to be determined, let alone the cellular triggers and underlying mechanisms. Although the broad expression of the channel in the cerebral cortex and the hippocampus may account for the increased incidence of epilepsy in certain kindreds with EA-1, the presence of Kv1.1 in the heart, skeletal muscle, retina, and pancreatic cells is noteworthy, in that no impairment of any of these tissues has been reported in EA-1 kindreds.

\section{TREATMENT}

Acetazolamide, a carbonic anhydrase inhibitor, is effective in reducing the frequency of ataxic episodes in some individuals. Lubbers et al. ${ }^{40}$ studied the response of an EA-1 family to acetazolamide. All six members were affected by paresthesia (in accordance with reports from other families ${ }^{10}$ ), and this caused the medication to be 
stopped in three patients. In the remaining three, acetazolamide reduced the number and severity of attacks, although some loss of efficacy did occur after 1 or 2 weeks.

The precise mechanism of action in EA-1 is unknown, although it has been postulated to alter the $\mathrm{pH}$ in the vicinity of the ion channel, causing hyperpolarization of the cell membrane and thus reducing neuronal excitablilty. ${ }^{10}$ In support of this model, an abnormally high $\mathrm{pH}$, correctable by acetazolamide, has been reported in the cerebellum by nuclear magnetic resonance spectroscopy of patients with episodic ataxia. ${ }^{75,76}$ However, these studies were performed in patients without genetic characterization, and thus were likely to be biased toward EA-2 because of its higher prevalence, so their relevance to EA-1 is unclear.

Long-term acetazolamide use can result in the formation of renal calculi. Hence, regular monitoring of renal function is necessary. Some patients also respond to various antiepileptic medications, including carbamazepine, phenytoin, and phenobarbitone. In one large Australian family, 8 of the 19 affected members were taking prophylactic carbamazepine and all noticed a significant reduction in the frequency of attacks. This response is comparable to that of a large Scottish family (described by Eunson et al. ${ }^{14}$ ) harboring the V404I mutation who all responded to carbamazepine. Again, the mechanisms of action remain to be elucidated, although these observations suggest that treatment may be specific to the mutations present, in that not all patients with EA-1 respond to these therapies.

\section{REFERENCES}

1. Ptacek LJ. Channelopathies: ion channel disorders of muscle as a paradigm for paroxysmal disorders of the nervous system. Neuromuscul Disord 1997;7:250-255.

2. Kullman DM. The neuronal channelopathies. Brain 2002;125: 1177-1195.

3. Ashcroft FM. Ion channels and disease: channelopathies. San Diego: Academic Press; 2000.

4. Davies NP, Hanna MG. Neurological channelopathies: diagnosis and therapy in the new millennium. Ann Med 1999;31:406-420.

5. Cannon SC. Ion-channel defects and aberrant excitability in myotonia and periodic paralysis. Trends Neurosci 1996;19:3-10.

6. Kullmann DM, Rea R, Spauschus A, Jouvenceau A. The inherited episodic ataxias: how well do we understand the disease mechanisms? Neuroscientist 2001;7:80-88.

7. Griggs RC, Moxley RT 3rd, Lafrance RA, McQuillen J. Hereditary paroxysmal ataxia: response to acetazolamide. Neurology 1978; 28:1259-1264.

8. Gancher ST, Nutt JG. Autosomal dominant episodic ataxia: a heterogeneous syndrome. Mov Disord 1986;1:239-253.

9. Griggs RC, Nutt JG. Episodic ataxias as channelopathies. Ann Neurol 1995;37:285-287.

10. Brunt ER, van Weerden TW. Familial paroxysmal kinesigenic ataxia and continuous myokymia. Brain 1990;113:1361-1382.

11. Browne DL, Gancher ST, Nutt JG, et al. Episodic ataxia/ myokymia syndrome is associated with point mutations in the human potassium channel gene, KCNA1. Nat Genet 1994;8:136140.
12. Browne DL, Brunt ER, Griggs RC, et al. Identification of two new KCNA1 mutations in episodic ataxia/myokymia families. Hum Mol Genet 1995;4:1671-1672.

13. Comu S, Giuliani M, Narayanan V. Episodic ataxia and myokymia syndrome: a new mutation of potassium channel gene Kv1.1. Ann Neurol 1996;40:684-687.

14. Eunson LH, Rea R, Zuberi SM, et al. Clinical, genetic, and expression studies of mutations in the potassium channel gene KCNA1 reveal new phenotypic variability. Ann Neurol 2000;48: 647-656.

15. Scheffer H, Brunt ER, Mol GJ, et al. Three novel KCNA1 mutations in episodic ataxia type I families. Hum Genet 1998;102:464466.

16. Spauschus A, Eunson L, Hanna MG, Kullmann DM. Functional characterization of a novel mutation in KCNA1 in episodic ataxia type 1 associated with epilepsy. Ann N Y Acad Sci 1999;868:442446.

17. Zuberi SM, Eunson LH, Spauschus A, et al. A novel mutation in the human voltage-gated potassium channel gene (Kv1.1) associates with episodic ataxia type 1 and sometimes with partial epilepsy. Brain 1999;122:817-825.

18. Knight MA, Storey E, McKinlay Gardner RJ, Hand P, Forrest SM. Identification of a novel missense mutation L329I in the episodic ataxia type 1 gene KCNA1: a challenging problem. Hum Mutat 2000;16:374.

19. Yue Q, Jen JC, Nelson SF, Baloh RW. Progressive ataxia due to a missense mutation in a calcium-channel gene. Am J Hum Genet 1997;61:1078-1087.

20. Jen J, Yue Q, Nelson SF, et al. A novel nonsense mutation in CACNA1A causes episodic ataxia and hemiplegia. Neurology 1999;53:34-37.

21. Ophoff RA, Terwindt GM, Vergouwe MN, et al. Familial hemiplegic migraine and episodic ataxia type- 2 are caused by mutations in the $\mathrm{Ca}^{2+}$ channel gene CACNL1A4. Cell 1996;87:543-552.

22. Denier C, Ducros A, Vahedi K, et al. High prevalence of CACNA1A truncations and broader clinical spectrum in episodic ataxia type 2. Neurology 1999;52:1816-1821.

23. Denier C, Ducros A, Durr A, Eymard B, Chassande B, TournierLasserve E. Missense CACNA1A mutation causing episodic ataxia type 2. Arch Neurol 2001;58:292-295.

24. Battistini S, Stenirri S, Piatti M, et al. A new CACNA1A gene mutation in acetazolamide-responsive familial hemiplegic migraine and ataxia. Neurology 1999;53:38-43.

25. Jouvenceau A, Eunson LH, Spauschus A, et al. Human epilepsy associated with dysfunction of the brain P/Q-type calcium channel. Lancet 2001;358:801-807.

26. Vahedi K, Joutel A, Van Bogaert P, et al. A gene for hereditary paroxysmal cerebellar ataxia maps to chromosome 19p. Ann Neurol 1995;37:289-293.

27. Van Dyke DH, Griggs RC, Murphy MJ, Goldstein MN. Hereditary myokymia and periodic ataxia. J Neurol Sci 1975;25:109-118.

28. Hanson PA, Martinez LB, Cassidy R. Contractures, continuous muscle discharges, and titubation. Ann Neurol 1977;1:120-124.

29. Vaamonde J, Artieda J, Obeso JA. Hereditary paroxysmal ataxia with neuromyotonia. Mov Disord 1991;6:180-182.

30. Hand PJ, Gardner RJ, Knight MA, Forrest SM, Storey E. Clinical features of a large Australian pedigree with episodic ataxia type 1 . Mov Disord 2001;16:938-939.

31. Van Bogaert P, Van Nechel C, Goldman S, Szliwowski HB. Acetazolamide-responsive hereditary paroxysmal ataxia: report of a new family. Acta Neurol Belg 1993;93:268-275.

32. Jen J, Kim GW, Baloh RW. Clinical spectrum of episodic ataxia type 2. Neurology 2004;62:17-22.

33. Baloh RW, Yue Q, Furman JM, Nelson SF. Familial episodic ataxia: clinical heterogeneity in four families linked to chromosome 19p. Ann Neurol 1997;41:8-16.

34. Hans M, Luvisetto $\mathrm{S}$, Williams ME, et al. Functional consequences of mutations in the human $\alpha 1 \mathrm{~A}$ calcium channel subunit linked to familial hemiplegic migraine. J Neurosci 1999;19:1610-1619.

35. Ducros A, Denier C, Joutel A, et al. The clinical spectrum of familial hemiplegic migraine associated with mutations in a neuronal calcium channel. N Engl J Med 2001;345:17-24. 
36. Vighetto A, Froment JC, Trillet M, Aimard G. Magnetic resonance imaging in familial paroxysmal ataxia. Arch Neurol 1988;45:547549.

37. Lee H, Wang H, Jen JC, Sabatti C, Baloh RW, Nelson SF. A novel mutation in KCNA1 causes episodic ataxia without myokymia. Hum Mutat 2004;24:536.

38. Kinali M, Jungbluth H, Eunson LH, et al. Expanding the phenotype of potassium channelopathy: severe neuromyotonia and skeletal deformities without prominent episodic ataxia. Neuromuscul Disord 2004;14:689-693.

39. Klein A, Boltshauser E, Jen J, Baloh RW. Episodic ataxia type 1 with distal weakness: a novel manifestation of a potassium channelopathy. Neuropediatrics 2004;35:147-149.

40. Lubbers WJ, Brunt ER, Scheffer H, et al. Hereditary myokymia and paroxysmal ataxia linked to chromosome 12 is responsive to acetazolamide. J Neurol Neurosurg Psychiatry 1995;59:400-405.

41. Smart SL, Lopantsev V, Zhang CL, et al. Deletion of the $\mathrm{K}_{\mathrm{V}} 1.1$ potassium channel causes epilepsy in mice. Neuron 1998;20:809819.

42. Biervert C, Schroeder BC, Kubisch C, et al. A potassium channel mutation in neonatal human epilepsy. Science 1998;279:403-406.

43. Charlier C, Singh NA, Ryan SG, et al. A pore mutation in a novel KQT-like potassium channel gene in an idiopathic epilepsy family. Nat Genet 1998;18:53-55.

44. Singh NA, Charlier C, Stauffer D, et al. A novel potassium channel gene, $K C N Q 2$, is mutated in an inherited epilepsy of newborns. Nat Genet 1998;18:25-29.

45. Lee WL, Biervert C, Hallmann K, Tay A, Dean JC, Steinlein OK. A $K C N Q 2$ splice site mutation causing benign neonatal convulsions in a Scottish family. Neuropediatrics 2000;31:9-12.

46. Schroeder BC, Kubisch C, Stein V, Jentsch TJ. Moderate loss of function of cyclic-AMP-modulated $K C N Q 2 / K C N Q 3 \mathrm{~K}^{+}$channels causes epilepsy. Nature 1998;396:687-690.

47. Bagetta G, Nistico G, Dolly JO. Production of seizures and brain damage in rats by $\alpha$-dendrotoxin, a selective $\mathrm{K}^{+}$channel blocker. Neurosci Lett 1992;139:34-40.

48. Juhng KN, Kokate TG, Yamaguchi S, et al. Induction of seizures by the potent $\mathrm{K}^{+}$channel-blocking scorpion venom peptide toxins tityustoxin-K $\alpha$ and pandinustoxin-K $\alpha$. Epilepsy Res 1999;34:177186.

49. Schulte U, Thumfart JO, Klocker N, et al. The epilepsy-linked Lgi1 protein assembles into presynaptic Kv1 channels and inhibits inactivation by $\mathrm{Kv} \beta 1$. Neuron 2006;49:697-706.

50. Fukata Y, Adesnik H, Iwanaga T, Bredt DS, Nicoll RA, Fukata M. Epilepsy-related ligand/receptor complex LGI1 and ADAM22 regulate synaptic transmission. Science 2006;313:1792-1795.

51. Litt M, Kramer P, Browne D, et al. A gene for episodic ataxia/ myokymia maps to chromosome 12p13. Am J Hum Genet 1994; 55:702-709.

52. Yu FH, Yarov-Yarovoy V, Gutman GA, Catterall WA. Overview of molecular relationships in the voltage-gated ion channel superfamily. Pharmacol Rev 2005;57:387-395.

53. Long SB, Campbell EB, Mackinnon R. Crystal structure of a mammalian voltage-dependent Shaker family $\mathrm{K}^{+}$channel. Science 2005;309:897-903.

54. Rettig J, Heinemann SH, Wunder F, et al. Inactivation properties of voltage-gated $\mathrm{K}^{+}$channels altered by presence of beta-subunit. Nature 1994;369:289-294.

55. Wang H, Kunkel DD, Martin TM, Schwartzkroin PA, Tempel BL. Heteromultimeric $\mathrm{K}^{+}$channels in terminal and juxtaparanodal regions of neurons. Nature 1993;365:75-79.

56. Wang H, Kunkel DD, Schwartzkroin PA, Tempel BL. Localization of Kv1.1 and Kv1.2, two K channel proteins, to synaptic terminals, somata, and dendrites in the mouse brain. J Neurosci 1994;14: $4588-4599$.
57. Coleman SK, Newcombe J, Pryke J, Dolly JO. Subunit composition of Kv1 channels in human CNS. J Neurochem 1999;73:849858.

58. Adelman JP, Bond CT, Pessia M, Maylie J. Episodic ataxia results from voltage-dependent potassium channels with altered functions. Neuron 1995;15:1449-1454.

59. D’Adamo MC, Liu Z, Adelman JP, Maylie J, Pessia M. Episodic ataxia type-1 mutations in the $\mathrm{hKv} 1.1$ cytoplasmic pore region alter the gating properties of the channel. EMBO J 1998;17:12001207.

60. Boland LM, Price DL, Jackson KA. Episodic ataxia/myokymia mutations functionally expressed in the Shaker potassium channel. Neuroscience 1999;91:1557-1564.

61. Zerr P, Adelman JP, Maylie J. Characterization of three episodic ataxia mutations in the human Kv1.1 potassium channel. FEBS Lett 1998;431:461-464.

62. Zerr P, Adelman JP, Maylie J. Episodic ataxia mutations in Kv1.1 alter potassium channel function by dominant negative effects or haploinsufficiency. J Neurosci 1998;18:2842-2848.

63. Imbrici P, Cusimano A, D’Adamo MC, De Curtis A, Pessia M. Functional characterization of an episodic ataxia type-1 mutation occurring in the S1 segment of hKv1.1 channels. Pflugers Arch 2003;446:373-379.

64. Rea R, Spauschus A, Eunson LH, Hanna MG, Kullmann DM. Variable $\mathrm{K}^{+}$channel subunit dysfunction in inherited mutations of KCNA1. J Physiol 2002;538:5-23.

65. Maylie B, Bissonnette E, Virk M, Adelman JP, Maylie JG. Episodic ataxia type 1 mutations in the human Kv1.1 potassium channel alter $\mathrm{hKv} \beta 1$-induced N-type inactivation. J Neurosci 2002;22: 4786-4793.

66. Imbrici P, D’Adamo MC, Kullmann DM, Pessia M. Episodic ataxia type 1 mutations in the KCNA1 gene impair the fast inactivation properties of the human potassium channels Kv1.4-1.1/ Kv $\beta 1.1$ and Kv1.4-1.1/Kv $\beta 1.2$. Eur J Neurosci 2006;24:30733083.

67. Trimmer JS, Rhodes KJ. Localization of voltage-gated ion channels in mammalian brain. Annu Rev Physiol 2004;66:477-519.

68. Herson PS, Virk M, Rustay NR, et al. A mouse model of episodic ataxia type-1. Nat Neurosci 2003;6:378-383.

69. Hisama F, Chen H, Von Hehn C, et al. Novel potassium channel (KCNA1) mutation in hereditary myokymia. Soc Neurosci Abstr 2006; Program no. 234.26/D64 (abstract).

70. Zhou L, Zhang CL, Messing A, Chiu SY. Temperature-sensitive neuromuscular transmission in Kv1.1 null mice: role of potassium channels under the myelin sheath in young nerves. J Neurosci 1998;18:7200-7215.

71. Veh RW, Lichtinghagen R, Sewing S, Wunder F, Grumbach IM, Pongs O. Immunohistochemical localization of five members of the Kv1 channel subunits: contrasting subcellular locations and neuron-specific co-localizations in rat brain. Eur J Neurosci 1995; 7:2189-2205.

72. Benatar M. Neurological potassium channelopathies. QJM 2000; 93:787-797.

73. Zhang CL, Messing A, Chiu SY. Specific alteration of spontaneous GABAergic inhibition in cerebellar Purkinje cells in mice lacking the potassium channel Kv1.1. J Neurosci 1999;19:2852-2564.

74. Chen G, Gao W, Reinert KC, et al. Involvement of Kv1 potassium channels in spreading acidification and depression in the cerebellar cortex. J Neurophysiol 2005;94:1287-1298.

75. Bain PG, O'Brien MD, Keevil SF, Porter DA. Familial periodic cerebellar ataxia: a problem of cerebellar intracellular $\mathrm{pH}$ homeostasis. Ann Neurol 1992;31:147-154.

76. Sappey-Marinier D, Vighetto A, Peyron R, Broussolle E, Bonmartin A. Phosphorus and proton magnetic resonance spectroscopy in episodic ataxia type 2. Ann Neurol 1999;46:256-259. 